\title{
Signal Transduction Pathways Mediated by Secreted and Non-Secreted Forms of Intact Insulin-Like Growth Factor Binding Protein-3 (IGFBP-3) and Its 1-97 N-Terminal Fragment in PC-3 Human Prostate Cancer Cells"
}

\author{
Hanief Mohammad Shahjee ${ }^{1 \#}$, Benjamin Kefas ${ }^{2}$, Nisan Bhattacharyya ${ }^{1}$, Mohamed K. Radwan ${ }^{3}$ \\ ${ }^{1}$ Diabetes Branch, NIDDK, National Institutes of Health, Bethesda, USA; ${ }^{2}$ Division of Neuro-Oncology, Neurology Department, \\ University of Virginia Health System, Charlottesville, USA; ${ }^{3}$ Department of Biochemistry and Biophysics, University of Rochester \\ Medical Center, Rochester, USA. \\ Email: "hanief_shahjee@urmc.rochester.edu
}

Received August $6^{\text {th }}, 2013$; revised September $3^{\text {rd }}, 2013$; accepted September $10^{\text {th }}, 2013$

Copyright (C) 2013 Hanief Mohammad Shahjee et al. This is an open access article distributed under the Creative Commons Attribution License, which permits unrestricted use, distribution, and reproduction in any medium, provided the original work is properly cited.

\begin{abstract}
Our previous results indicated that both the secreted and the intracellular form of full length and 1-97 N-terminal fragment of IGFBP-3 induce apoptosis in PC-3 human prostate cancer cells in an IGF-dependent and independent manner. This study was undertaken to delineate possible down-stream signaling pathways that are involved in this process. Intact IGFBP-3 and its N-terminal 1-97 fragments with or without a signal propeptide were fused to YFP and expressed in PC-3 human prostate cancer cells. In some cases, the putative IGF-binding site was presented in full length IGFBP-3 and its N-terminal fragment was also mutated. Extent of apoptosis was quantified using FACS. Up-regulation of total Stat- 1 and activation of phospho-Stat- 1 were shown by western blot. TGF- $\beta$ signal was measured by luciferase reporter assay. Results from inhibitor studies indicated that both the Caspase 8 and caspase 9 pathways are involved in IGFBP-3 (non-secreted form) which induced apoptosis in PC-3 cells. Exogenous addition of IGFBP-3 to PC-3 cells increased Stat-1 protein expression/tyrosine phosphorylation. Interestingly, results also showed that knockdown of Stat-1 by siRNA potentiated the IGFBP-3 induced apoptosis in PC-3 cells. In addition, both full-length IGFBP-3 and its 1-97 Nterminal fragments inhibited TGF- $\beta$ signaling in these cells. This is the first report that compares the signal transduction pathways involved in apoptotic pathways mediated by IGFBP-3 in PC-3 human prostate cancer cells. Non-secreted form of full length IGFBP-3 and its N-terminal fragments induced apoptosis in PC-3 cells via activation of caspase 8 and caspase 9. Although, only non-secreted form of IGFBP-3 is involved in inducing apoptosis in PC-3 cells via caspase 8 and caspase 9 activation pathways but both secreted and non-secreted forms of IGFBP-3 are involved in modulating Stat-1 and TGF- $\beta$ pathways to induce apoptotic actions in PC-3 cells. Non-secreted intact IGFBP-3 and its N-terminal fragments induced apoptosis in PC-3 cells via activation of caspase 8 and caspase 9 pathways. Modulation in STAT-1 and TGF- $\beta$ pathways may also be important for IGFBP-3 induced apoptosis in PC-3 cells in general. These studies clearly demonstrate that secreted and non-secreted FL and 1-97 N-terminal fragments induce apoptosis in PC-3 cells by regulating different mechanistic pathways.
\end{abstract}

Keywords: N-Terminal Fragment; Apoptosis; Caspases; Human Prostate Cancer Cells

\section{Introduction}

Insulin-like growth factor binding protein-3 (IGFBP-3),

\footnotetext{
"This work was supported by an intramural grant from NIDDK, NIH. Authors' contributions: HMS carried out all experiments for these studies. NB supervised the research and inter-pretation of the data was carried out by HMS and NB. HMS, BK, NB and MKR made the final draft for the paper.

${ }^{\#}$ Corresponding author.
}

the most abundant protein of the six IGFBPs, is an important modulator of insulin-like growth factor (IGF) biological activity. IGFBP-3 binds to IGF-I and IGF-II with high affinities and restricts their bioavailability by forming stable ternary complexes with an acid-labile subunit. These complexes have been reported to be stable in plasma [1]. These complexes play major roles by preventing the IGFs from activating IGF-I receptors on target cells 
and stimulating cell proliferation and survival $[2,3]$. Several reports have indicated that IGFBP-3 induces cell death and inhibits cell proliferation in various cell types, including prostate cancer cells (PC-3 cells), and it's independent of its IGF-I binding [4-6]. IGFBP-3 is a secreted protein but it can be internalized to the nucleus when it's added to cells. Other reports have indicated that the presence of IGFBP-3 in the cytoplasm [5,7] or in the mitochondria [8] can induce cell death. Although the IGFBP-3 receptor has not been identified, several signal transduction mechanisms responsible for biological actions of IGFBP-3 have been implicated [9-12]. IGFBP3 's availability to cells and tissues is also regulated by proteolysis. Proteolysis of IGFBP-3 protein was initially demonstrated in serum of pregnant women, where it circulates primarily in low molecular weight forms [13]. These fragments bind to IGF with lower affinities, thereby increasing the limited availability of IGF to target receptors. Interestingly, various IGFBP-3 fragments have been reported to mediate direct stimulatory or inhibitory actions at the target cells [14].

Results from our previous study have demonstrated that when full-length IGFBP-3 is added exogenously to PC-3 cells, it can be processed into a small N-terminal fragment (amino acids 1-97). Our results also demonstrated that expression of 1-97 N-terminal IGFBP-3 fragments induces apoptosis in these cells [15]. Irrespective of the presence of a signal peptide, expression of either the wild-type intact IGFBP-3 and N-terminal 1-97 fragment or an IGF-nonbinding mutant $6 \mathrm{~m}$ (mutations in six IGF-binding amino acid residues) fusion proteins caused a loss of cell viability indicative of apoptosis. However, the signal transduction mechanisms specific to either the full-length or the 1-97 N-terminal fragment of IGFBP-3 have not been studied.

In this study, not only we confirmed the involvement of secreted as well as non-secreted forms of IGFBP-3 in inducing apoptosis in PC-3 cells, but also we studied the possible signaling pathways modulated by these various forms of IGFBP-3 during the process. We examined the induction of apoptosis in the presence or absence of caspase- 8 and -9 inhibitors. Surprisingly, we found that intracellular form of intact and 1-97 N-terminal fragments of IGFBP-3 (wild-type or mutant) could induce apoptosis in a caspase- 8 and -9 dependent manner in comparison to secreted form of IGFBP-3. Our results also demonstrate that exogenous addition of IGFBP-3 up-regulates Stat-1 protein levels and its tyrosine phosphorylation in a timedependent fashion. To better understand the role of STAT-1 in IGFBP-3 induced apoptosis in PC-3 cells, we knocked down the Stat-1 expression by using STAT-1 siRNA technique in PC-3 cells. In contrast to a previous report [10], our results (Figure 1) showed that STAT1 siRNA treatment further potentiates IGFBP-3 (secreted

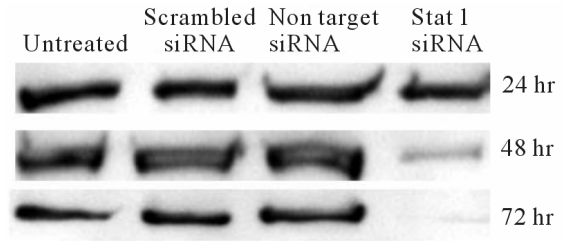

(a)

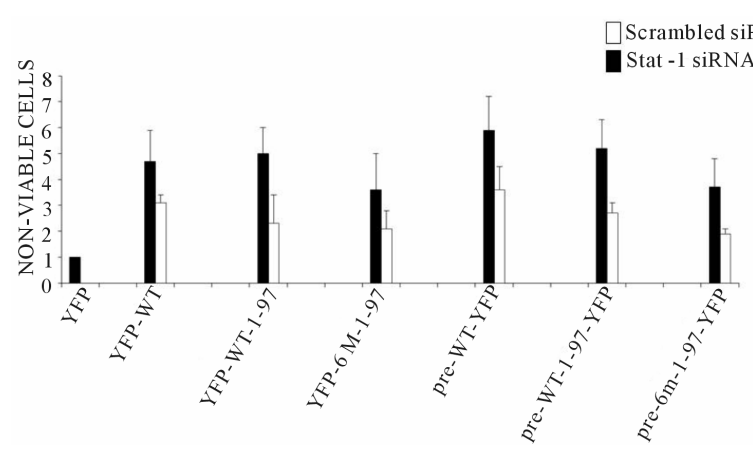

(b)

Figure 1. siRNA knockdown of Stat-1 protein in PC-3 cells. (a) Stat-1 protein expression levels were reduced after transfection with Stat-1 siRNA. PC-3 cells were transfected with no DNA (Untreated; Lane 1), scrambled siRNA (Lane 2), non-target (NT) siRNA (lane 3), and Stat-1 siRNA (Lane 4) for 24, 48, and $72 \mathrm{~h}$. Whole cell extracts were prepared and western blot analyses were performed to examine the Stat-1 protein expression levels by using an anti-human Stat-1 antibody. Stat-1 protein expression level is decreased after 48 and $72 \mathrm{~h}$ of transfection. Blot is representative result of three independent experiments. Transfection of Stat1 siRNA potentiates IGFBP-3-mediated apoptosis in PC-3 cells. (b) PC-3 cells were first transfected with either scrambled (open bars) or Stat-1 siRNA (black bars) for $24 \mathrm{~h}$ and subsequently with various constructs expressing the fulllength and/or N-terminal fragments of IGFBP-3 protein for another $48 \mathrm{~h}$ (total $72 \mathrm{~h}$ ). Results from FACS analyses are shown. Percentages of non-viable cells are indicated. Each experiment was performed in duplicate on three separate occasions. Data is expressed as mean \pm SEM.

and non-secreted), which induced apoptosis in these cells, thereby suggesting that Stat-1 may be an important target molecule for IGFBP-3, which induced PC-3 cell death. In addition, when we transfected a PC-3 stable cell line expressing CAGA-TGF- $\beta$ reporter luciferase gene with various IGFBP-3 constructs (Figure 2), we observed that both secreted as well as non-secreted forms of IGFBP-3 constructs inhibited TGF- $\beta$ signal in these cells, thereby providing evidence that IGFBP-3 also exploits the TGF- $\beta$ signaling pathways for its apoptotic action in PC-3 cells.

\section{Materials and Methods}

\subsection{Materials}

The caspase 8-selective inhibitor Z-IETD-fmk, the caspase 9-selective inhibitor Z-LEHD-fmk, and annexinV- 


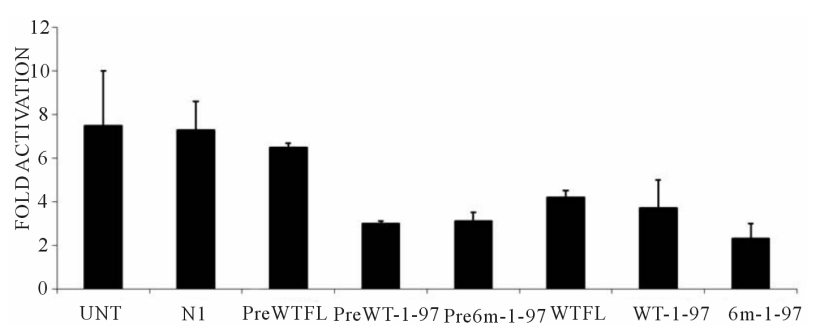

Figure 2. Transient transfection of IGFBP-3 constructs reduces TGF $\beta$ signaling in $\mathrm{PC}-3$ cells. $\mathrm{PC}-3$ cell-line stably expressing (CAGA) 12 tkluc (a TGF $\beta$-responsive promoter construct) was used for this experiment. These cells were transfected with the indicated IGFBP-3 constructs and were subsequently treated with TGF $\beta(10 \mathrm{ng} / \mathrm{ml})$ or carrier for 24 h. Dual luciferase (renilla luciferase was used as the transfection control) assays were performed. Fold activation (luciferase activity) values (+/-TGF $\beta$ added) obtained for each sample are shown. There is decreased TGF $\beta$ signaling in cells transfected with constructs that are expressing intracellular full-length and N-terminal 1-97 IGFBP-3. Each experiment was repeated three times in triplicates. Data is expressed as mean \pm SEM.

APC were purchased from BD Pharmingen (San Diego, CA). Recombinant glycosylated human IGFBP-3 was obtained from R \& D Systems (Minneapolis, MN). Lipofectamine plus transfection reagent was obtained from Invitrogen (Carlsbad, CA). TGF- $\beta$ and mouse $\beta$-actin antibody were purchased from Sigma Aldrich (St Louis, MO). Stat-1 siRNA was purchased from Dharmacon (Lafayette, $\mathrm{CO})$. Rabbit anti-human antibodies against total and tyrosine phosphorylated (Y701) Stat-1 proteins were obtained from Cell Signaling Technology (Danvers, MA).

\subsection{Transfection}

PC-3 cells $\left(1.5 \times 10^{5}\right.$ cells/6-well $)$ were grown to $70 \%$ $80 \%$ confluence in F12K medium containing $10 \%$ fetal bovine serum (FBS). Cells were transfected $\left(37^{\circ} \mathrm{C}, 3 \mathrm{~h}\right)$ in $1 \mathrm{ml}$ of serum-free medium containing $500 \mathrm{ng}$ of different plasmid constructs using Lipofectamine Plus (Invitrogen). The cells were recovered by adding $1.7 \mathrm{ml}$ of F12K medium containing $0.3 \mathrm{ml}$ of FBS and were incubated at $37^{\circ} \mathrm{C}$ for $48 \mathrm{~h}$ unless otherwise specified.

\subsection{Whole Cell Extract Preparation}

PC-3 cells were incubated with noted concentrations of recombinant IGFBP-3 (R \& D Systems, Minneapolis, $\mathrm{MN}$ ) for indicated periods. After incubation, cells were washed with phosphate-buffered saline (PBS) and were lysed with $100 \mu \mathrm{l}$ per $20-\mu 1$ cellpellet of whole cell extract buffer (10 mM HEPES, pH 7.4, 10\% glycerol, 250 $\mathrm{mM} \mathrm{NaCl}, 1 \mathrm{mM}$ EDTA, $0.1 \%$ Nonidet P-40, $1 \mathrm{mM}$ dithiothreitol, and $1 \times$ protease inhibitor mixture) at $4{ }^{\circ} \mathrm{C} \mathrm{C}$ for $20 \mathrm{~min}$. Lysates were vortexedat high speed for $15 \mathrm{~s}$ and placed on ice for $5-10 \mathrm{~min}$. After centrifugation $\left(12,000 \mathrm{rpm}, 5 \mathrm{~min}, 4^{\circ} \mathrm{C}\right.$ ), whole cell extracts (supernatants) were stored at $-70^{\circ} \mathrm{C}$.

\subsection{Western Blot}

Protein concentrations were measured using the DC protein assay (Bio-Rad). Proteins were fractionated using $4 \%-20 \%$ SDS-PAGE (Bio-Rad) under reducing conditions. For whole cell extracts, $50 \mu \mathrm{g}$ of protein was loaded per lane. Specific proteins were identified by western blotting using Rabbit anti-Stat-1 antibody or Rabbit pStat1 antibody (Cell Signaling Technology, Danvers, MA). Equal loading of the protein was confirmed by using mouse anti-human $\beta$-actin antibody (Sigma, St. Louis, MO). Protein bands were detected by using SuperSignal West Pico Chemiluminescent Substrate (Pierce, Rockford, IL).

\section{5. siRNA Transfection}

PC- 3 cells were plated in antibiotic-free F12K medium $\left(1.0 \times 10^{5} \mathrm{cells} / \mathrm{ml}\right.$ for 12 -well plate $)$ for transfection. Cells were transfected with either Stat-1, non-targetor scrambled siRNA following a procedure provided by the supplier (Dharmacon). Cells were incubated for $24-96 \mathrm{~h}$ for protein analysis. For cell-death analysis experiments, cells were first transfected with STAT-1 siRNA or scrambled siRNA for $24 \mathrm{~h}$ and then were transfected with the indicated IGFBP- 3 constructs in serum-free media for $3 \mathrm{~h}$ and incubated in serum containing media for $48 \mathrm{~h}$ for FACS analysis.

\subsection{Fluorescence Activated Cell Sorting (FACS) Analysis}

After transfecting PC-3 cells with IGFBP-3 constructs for $3 \mathrm{hrs}, 20 \mu \mathrm{M}$ each of caspase 8 and caspase 9 inhibitor was added before cells were incubated at $37^{\circ} \mathrm{C}$ in serum containing media for recovery. For analysis of apoptosis, both attached and floating cells were collected. The cell pellets were washed with $1 \times$ binding buffer $(10 \mathrm{mM}$ HEPES, pH 7.4, $140 \mathrm{mM} \mathrm{NaCl}, 2.5 \mathrm{mM} \mathrm{CaCl} 2$ ) (BD Pharmingen, San Diego, CA) and were stained using 300 - $500 \mu 1$ of binding buffer containing $5 \mu 1$ of annexin V-APC at room temperature for $15-30 \mathrm{~min}$. Cells were analyzed using a CyAnLX flow cytometer equipped with Summit software (DakoCytomation, Fort Collins, CO).

\subsection{Luciferase Reporter Assay}

PC-3 cells were transfected with the TGF- $\beta$-responsive reporter construct (CAGA) 12 tkluc plasmid DNA for 3 hrs. Cells were recovered in serum-containing media and cells were incubated for overnight at $37^{\circ} \mathrm{C}$. Selective marker G418 was added and cells that stably expressed this construct were selected after 3 weeks of incubation with G418. One of the stable cell (CAGA 11), was tran- 
siently transfected with YFPN1, PrewtFL, Prewt (1-97), Pre6m (1-97), WtFL, Wt (1-97), and 6m (1-97) along with Renilla luciferase construct (transfection control) for $3 \mathrm{~h}$ followed by the recovery in $10 \%$ serum containing F12K media for $24 \mathrm{~h}$. Cells were washed and TGF- $\beta$ (10 $\mathrm{ng} / \mathrm{ml}$ ) was added to fresh serum-free media overnight at $37^{\circ} \mathrm{C}$. Cells were washed, lysed and luciferase assay was performed using a dual luciferase assay system (Promega, Madison, WI). Luciferase activities were normalized by using renilla luciferase amounts present in each extract.

\subsection{Statistical Analysis}

All data were presented as means \pm standard deviation (SD). The significance of the difference between mean values was determined by an analysis of variance with $p$ $<0.05$ considered significant

\section{Results}

\subsection{Addition of Inhibitors Specific for Caspase-8 and Caspase-9 Reduces IGFBP-3-Induced Apoptosis in PC-3 Cells}

Results from our previous study demonstrated that the expression of various IGFBP-3 fusion protein constructs induced apoptosis in PC-3 cells. [5,15]. In order to understand the mechanism(s) by which full-length IGFBP3 and its N-terminal 1-97 fragment induce apoptosis, we transfected PC-3 cells with various IGFBP-3 constructs with or without a signal peptide. Apoptosis was determined in untreated cells (red bars) and in the presence of $20 \mu \mathrm{m}$ of caspase-8 (IETD; yellow bars) and $20 \mu \mathrm{m}$ of caspase-9 (LEHD, green bars) specific inhibitors. The number of apoptotic cells was determined by Annexin-V staining (FACS). Results indicated that the addition of either caspase 8 or 9 inhibitor significantly inhibited IGFBP-3-induced apoptosis in PC-3 cells (Figure 3). These results clearly shows that Intracellular form of full length and 1-97 N-terminal fragments of WT and $6 \mathrm{~m}$ IGFBP-3 induce apoptosis in PC-3 cancer cells using both caspase- 8 and caspase-9 pathway which is not the case with secreted form of Intact and 1-97 N-terminal fragment of IGFBP-3. These results also confirm that IGFBP-3 does not need to depend on the availability of IGF or be secreted to induce apoptosis in PC-3 cells and interestingly secreted form of IGFBP-3 is not involved in inducing apoptosis via caspase 8 and caspase 9 activation pathways.

\subsection{Addition of Exogenous IGFBP-3 Increases the Expression of Stat-1 Protein Level and Its Tyrosine Phosphorylation (Y701) in PC-3 Cells}

A previous report [10] has shown that the addition of

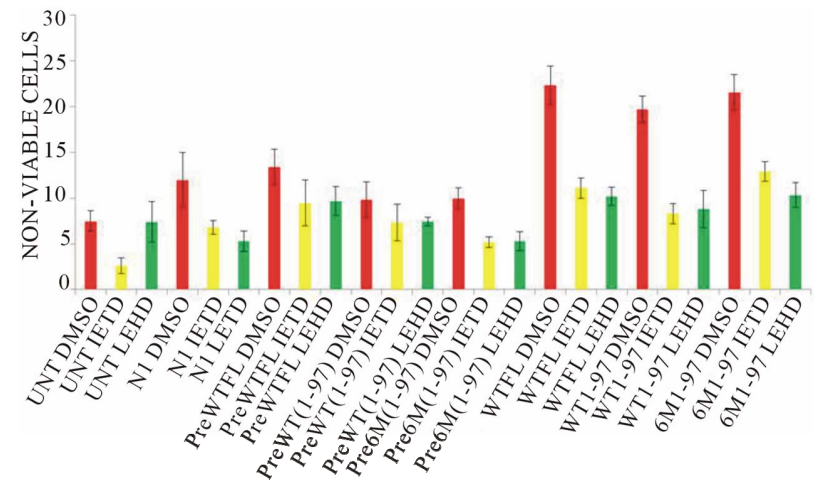

Figure 3. IGFBP-3 induced apoptosis in PC-3 cells is inhibited by inhibitors specific for Caspase-8 and Caspase-9. PC-3 cells were transfected with plasmid constructs directing the expression of either the full-length IGFBP-3 or its N-terminal 1-97 fragments. Cells were subsequently treated with either DMSO (vehicle; Red bars) or $10 \mu \mathrm{M}$ IETD (caspase-8 inhibitor; yellow bars) and LEHD (caspase-9 inhibitor; green bars) for $48 \mathrm{~h}$. Results from FACS analyses (Annexin-V+ cells) are shown. Percentages of non-viable cells are indicated. Figure 3 showed significant inhibition of IGFBP-3 induced apoptosis in PC-3 cells in the presence of caspase-8 and/or caspase-9 inhibitors. Experiments were performed in triplicate twice and error bars represent mean \pm SEM.

IGFBP-3 induces apoptosis and differentiation via STAT1 in rat chondroprogenitor cells. In order to investigate the roles of STAT-1 signaling pathways in IGFBP-3 induced apoptosis in PC-3 cells, we incubated the cells with different concentrations of exogenous recombinant IGFBP-3. Expression of total Stat-1 levels in PC-3 cells were increased in a dose-dependent manner, peaking after $50 \mathrm{ng} / \mathrm{ml}$ of IGFBP-3 (Figure 4(a)) addition. There was also a transient increase in tyrosine-phosphorylated Stat-1 (pY701 STAT-1) levels within 10 min of incubation with $50 \mathrm{ng}$ of IGFBP-3 (Figure 4(b)). These results demonstrate that addition of IGFBP-3 can elevate the expression levels as well as pY701 Stat-1 in PC-3 cells indicating the involvement of Stat-1 signaling pathways.

\subsection{Introduction of Stat-1 siRNA Potentiates the IGFBP-3-Induced Apoptosis in PC-3 Cells}

In order to better understand the roles of STAT-1 signal pathways in IGFBP-3 induced apoptosis in PC-3 cells, we first tested the effectiveness of a siRNA to block the expression of Stat-1 in these cells. Western blot analysis showed marked decrease in Stat-1 protein levels after 48 and $72 \mathrm{~h}$ of siRNA transfection in PC-3 cells (lanes marked as Stat-1siRNA) compared to cells with no siRNA treatment or transfected either with a scrambled siRNA or a non-target siRNA (Figure 1(a)). There was also a significant decrease in Stat- 1 mRNA levels after $24 \mathrm{hrs}$ of siRNA transfection in PC-3 cells (data not shown 


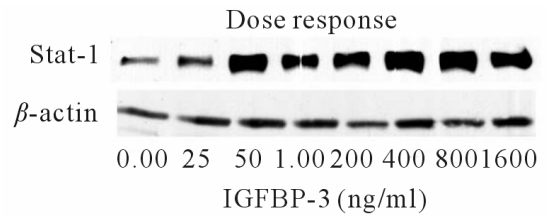

(a)

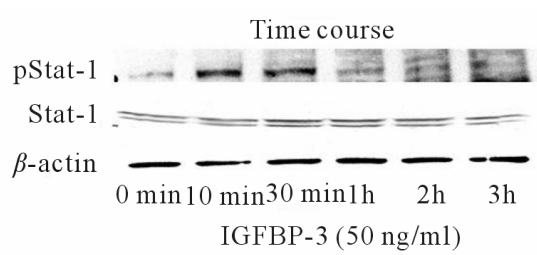

(b)

Figure 4. Addition of exogenous IGFBP-3 induced Stat-1 protein expression as well as its tyrosine phosphorylation (pY701) in PC-3 cells. (a) PC-3 cells were treated with exogenous recombinant IGFBP-3 (in $\mathrm{ng} / \mathrm{ml}$ are indicated below each lane) for $1 \mathrm{~h}$. Whole cell extracts were prepared and a western blot analysis was performed. Anti-human Stat-1 antibody was used to examine the Stat-1 protein (91 kDa) (upper panel) and $\beta$-actin (42 kDa) (lower panel) expression levels in each sample. There is a dose-dependent increase of Stat-1 protein expression level in the presence of exogenously added recombinant IGFBP-3. This data is a representative result of three independent experiments. (b) IGFBP-3 treatment causes transient increase in Stat-1 tyrosine phosphorylation (pY701) PC-3 cells were treated with $50 \mathrm{ng} / \mathrm{ml}$ of IGFBP-3 for indicated periods of time. Whole cell extracts were prepared and western blot was performed by using an antibody against pY701 STAT-1(upper panel; indicated by a $91 \mathrm{kDa}$ ) (upper panel) and unmodified STAT-1 (middle panel, 91 kDA). The experiment was repeated three times. The blot was stripped and was reused to detect for the $\beta$-actin (lower panel; indicated by a $42 \mathrm{kDa}$ protein) level using an anti-human $\beta$-actin antibody and that served as the loading control. Blot is a representative result of three independent experiments.

shown) Secondly, cell viability was determined in PC cells transfected first with either STAT-1 siRNA (black bars) or a scrambled siRNA (white bars) and then with full length and various 1-97 N-terminal IGFBP-3 constructs. FACS analysis results showed that the IGFBP3-induced apoptosis was potentiated in cells transfected with Stat-1 siRNA (Figure 1(b)), a result that is in contradiction with a previous observation [10] but this report confirms that Stat-1 plays an important role in IGFBP-3 induced apoptosis in PC-3 cells.

\subsection{Expression of Intracellular IGFBP-3 Constructs Inhibits TGF- $\beta$ SIgnaling in PC-3 Cells}

TGF- $\beta$ has been implicated in several cellular processes including apoptosis and proliferation $[16,17]$. In order to determine and delineate the involvements of TGF- $\beta$ sig- naling pathways, we compared the effects of intact IGFBP-3 or its N-terminal 1-97-IGFBP-3-YFP fragments in PC-3 cells. First, several PC-3 cell-lines that stably expressed (CAGA) 12 tkluc construct, a TGF- $\beta$-responsive luciferase reporter system, were created. One of these clonal cell-lines was selected for transfection with various constructs (WTFL IGFBP-3/1-97 N-terminal fragment and 6m FL IGFBP-3/ 1-97 N-terminal fragment) that express IGFBP-3 with or without its signal peptide. Extent of TGF- $\beta$ signals were measured by luciferase output with without the addition of TGF- $\beta$. There was significant inhibitions of TGF- $\beta$-mediated (CAGA) 12 luciferase activities in cells transfected with YFP-WTFL-IGFBP-3, YFP-WT-1-97-IGFBP-3, or Pre-WT-1-97IGFBP-3-YFP in comparison to cells transfected with YFP empty vector or untransfected control (Figure 2). Similar results were observed with YFP-6m-1-97-IGFBP3 and Pre-6m-1-97-IGFBP-3-YFP in which the IGF-binding site had been mutated, indicating that the inhibition of TGF- $\beta$ signaling occurs through an IGF-independent mechanism. Interestingly, cells transfected with Pre-WTFL-IGFBP-3-YFP had a little effect. Whole cell extracts and media collected from these transfected cells were examined and equivalent expression of IGFBP-3 fusion protein was observed in each sample (data not shown). Full-length IGFBP-3 as well as its 1-97 N-terminal fragment that expressed only intracellular protein inhibited TGF- $\beta$ signaling in PC- 3 cells. This indicates that TGF- $\beta$ signaling pathways are involved in cellular actions of IGFBP-3.

\section{Discussion}

IGFBP-3, the most abundant IGFBP in human serum, acts not only as a carrier of IGFs prolonging their halflives in circulation, but also functions as a modulator of IGF activity by regulating their availability to interact with IGF receptors [18]. However, there is increasing evidence that IGFBP-3 may have its own biological actions. For example, IGFBP-3 can inhibit cell proliferation in an IGF-independent manner [4,19,20]. Conceptually, IGFBP-3 can exert its actions on target cells by: 1) inducing apoptosis, 2) regulating cell cycle and proliferation, and 3) inducing cross-talk with major signal transduction pathways. Mechanisms for inducing apoptosis, in part, have been demonstrated by studies showing that IGFBP-3 increases the ratio of proapoptotic to antiapoptotic proteins in breast cancer cells [21]. As a regulator of the cell cycle, IGFBP-3 has been shown to modulate the induction of the cyclin-dependent kinase inhibitory protein $\mathrm{p} 21 / \mathrm{WAF} / \mathrm{CIP} 1$ in LNCaP prostate cancer cells [22].

Previous studies demonstrated that caspase- 8 can activate caspase- 3 and -7 directly and/or through triggering the activation of caspase- 9 by the release of mitochon- 
drial cytochrome c [23]. Being consistent with our previous studies [5], current data suggest that non-secreted IGFBP-3 induced apoptosis in PC-3 cells, is mediated by caspase- 8 as well as the caspase- 9 pathways. Our results indicate that apoptosis induced by non-secreted IGFBP-3 as compared to secreted form could be blocked after addition of caspase- 8 and -9 inhibitors, indicating that both initiator caspase pathways are involved in this process.

Several studies have demonstrated that full-length IGFBP-3 can induce various signaling pathways $[6,17,24$, 25]. In this regard, $\mathrm{PC}-3$ cells were transfected with different IGFBP-3 constructs and then treated with inhibitors specific for PI-3K and p38 MAPK. Results from FACS analyses indicated that there was little or no difference in the extent of cell death (data not shown), indicating that the PI-3K and p38 MAPK signaling pathways may not be involved in IGFBP-3 mediated cell death in PC-3 cells.

Another signaling molecule (Stat-1) has been implicated in IGFBP-3 induced apoptosis in rat chondroprogenitor cells [10], this study led us to demonstrate the role of Stat-1 in IGFBP-3 induced apoptosis in PC-3 human prostate cancer cells. Dose response experiment showed increased Stat-1 protein expression at higher concentrations of exogenous IGFBP-3. Tyrosine phosphorylation of Stat-1 was also enhanced at higher concentrations of exogenous IGFBP-3 in a time dependent manner (Figures 2(a) and (b)). In contrast to this previous report, our results indicated that STAT-1 knock-down potentiated the apoptotic effects of various IGFBP-3 constructs in PC-3 human prostate cancer cells (Figures 3(a) and (b)). The data suggest that Stat-1 protein might be playing a protective role in PC-3 cells and the data also suggest that the involvement of STAT-1 in apoptosis and proliferation might be cell type dependent.

IGFBP-3 has shown to interact with transforming growth factor- $\beta$ (TGF- $\beta$ ) cell surface receptors. In mink lung epithelial cells and other cell-types, IGFBP-3 binds to TGF $\beta$-receptor typeV (TGF $\beta$-RV) [12]. An IGFBP-3 mediated inhibitory effect on growth involving this particular receptor has been proposed, but mechanisms of action have not been fully elucidated. In this pathway, IGFBP-3 also binds to and activates intracellular signaling via the TGF- $\beta$ RII and TGF- $\beta$ RI heteromeric complex $[24,25]$. Addition of IGFBP-3 activated Smad2 phosphorylation and inhibited cell growth in these cells. Studies have also indicated that the addition of TGF- $\beta$ can potentiate IGFBP-3-induced cell death in PC-3 cells (6). In that regard, our results demonstrated that the expression of IGFBP-3 constructs could significantly inhibit TGF- $\beta$ signaling (Figure 2) in PC-3 cells. This implies that IGFBP-3 might interfere with TGF- $\beta$ signaling pathways. It is also interesting to note that this inhibition was more prominent in cells where IGFBP-3 is expressed intra-cellularly. Results from our previous studies [5,15] clearly indicated that the IGFBP-3-YFP fusion proteins expressed from Pre wt 1-97, Pre6m 1-97 WtFL, Wt 1-97, and $6 \mathrm{~m}$ 1-97 constructs are present predominantly inside the cells whereas Prewt FL protein was present outside in the media. How these intracellular proteins can interfere with TGF- $\beta$ signals is not clear yet. Although we did not measure differential Smad activation levels in these cells, our data clearly suggest that TGF- $\beta$ signaling pathways are playing an important role in IGFBP-3 induced biological actions in these cells. Future studies would be needed to elucidate the roles of IGFBP-3 in TGF- $\beta$ signaling by comparing the gene and protein expression profile in these cells. Our data indicate that full length IGFBP-3 and its N-terminal fragments induced the apoptosis of PC-3 cells through the modulations of caspases 8 , 9. STAT- 1 and TGF- $\beta$ signal pathways are also involved. It also suggests the modulation of STAT-1 and TGF- $\beta$ pathways as possible therapy for prostate cancer.

\section{Acknowledgements}

We gratefully acknowledge Drs. William Chong (NIDCR, NIH) and Maria Mochin-Peters (University of Maryland, Baltimore) for comments and suggestions.

\section{REFERENCES}

[1] T. Laursen, A. Flyvbjerg, J. O. L. Jorgensen and R. C Baxter, "Stimulation of the 150-Kilodalton Insulin-Like Growth Factor-Binding Protein-3 Ternary Complex by Continuous and Pulsatile Patterns of Growth Hormone (GH) Administration in GH-Deficient Patients," The Journal of Clinical Endocrinology \& Metabolism, Vol. 85, No. 11, 2000, pp. 4310-4314. http://dx.doi.org/10.1210/jc.85.11.4310

[2] M. M. Rechler and D. R. Clemmons, "Regulatory Actions of Insulin-Like Growth Factor-Binding Proteins," Trends Endocrinology Metabolism, Vol. 9, No. 5, 1998, pp. 176183. http://dx.doi.org/10.1016/S1043-2760(98)00047-2

[3] S. M. Firth and R. C. Baxter, "Cellular Actions of the Insulin-Like Growth Factor Binding Proteins," Endocrinology Review, Vol. 23, No. 6, 2002, pp. 824-854. http://dx.doi.org/10.1210/er.2001-0033

[4] J. Hong, G. Zhang, F. Dong and M. M. Rechler, "Insulin-Like Growth Factor (IGF)-Binding Protein-3 Mutants That Do Not Bind IGF-I or IGF-II Stimulate Apoptosis in Human Prostate Cancer Cells," Journal of Biological Chemistry, Vol. 277, No. 12, 2002, pp. 10489-10497. http://dx.doi.org/10.1074/jbc.M109604200

[5] N. Bhattacharyya, K. Pechhold, H. Shahjee, et al., "NonSecreted Insulin-Like Growth Factor Binding Protein-3 (IGFBP-3) Can Induce Apoptosis in Human Prostate Cancer Cells by IGF-Independent Mechanisms without Being Concentrated in the Nucleus," Journal of Biological 
Chemistry, Vol. 281, No. 34, 2006, pp. 24588-24601. http://dx.doi.org/10.1074/jbc.M509463200

[6] R. Rajah, B. Valentinis and P. Cohen, "Insulin-Like Growth Factor (IGF)-Binding Protein-3 Induces Apoptosis and Mediates the Effects of Transforming Growth Factor-Beta1 on Programmed Cell Death through a p53- and IGFIndependent Mechanism," Journal of Biological Chemistry, Vol. 272, No. 18, 1997, pp. 12181-12188. http://dx.doi.org/10.1074/jbc.272.18.12181

[7] A. J. Butt, K. A. Fraley, S. M. Firth and R. C. Baxter, "IGF-Binding Protein-3-Induced Growth Inhibition and Apoptosis Do Not Require Cell Surface Binding and Nuclear Translocation IN Human Breast Cancer Cells," Endocrinology, Vol. 143, No. 7, 2002, pp. 2693-2699. http://dx.doi.org/10.1210/en.143.7.2693

[8] K.W.Lee, L. Ma, X. Yan, et al., "Rapid Apoptosis Induction by IGFBP-3 Involves an Insulin-Like Growth FactorIndependent Nucleomitochondrial Translocation of RXRalpha/Nur77," Journal of Biological Chemistry, Vol. 280, No. 17, 2005, pp. 16942-16948. http://dx.doi.org/10.1074/jbc.M412757200

[9] L. J. Schedlich, T. F. Young, S. M. Firth and R. C. Baxter, "Insulin-Like Growth Factor-Binding Protein (IGFBP)-3 and IGFBP-5 Share a Common Nuclear Transport Pathway in T47D Human Breast Carcinoma Cells," Journal of Biological Chemistry, Vol. 273, No. 29, 1998, pp. 1834718352. http://dx.doi.org/10.1074/jbc.273.29.18347

[10] A. Spagnoli, M. Torello, S. R. Nagalla, et al., "Identification of STAT-1 as a Molecular Target of IGFBP-3 in the Process of Chondrogenesis," Journal of Biological Chemistry, Vol. 277, No. 21, 2002, pp. 18860-18867. http://dx.doi.org/10.1074/jbc.M200218200

[11] G. Zappalà and M. M. Rechler, "IGFBP-3, Hypoxia and TNF-Alpha Inhibit Adiponectin Transcription," Biochemical and Biophysical Research Communications, Vol. 382, No. 4, 2009, pp. 785-789.

http://dx.doi.org/10.1016/j.bbrc.2009.03.112

[12] S. M. Leal, S. S. Huang and J. S. Huang, "Interactions of High Affinity Insulin-Like Growth Factor-Binding Proteins with the Type V Transforming Growth Factor-Betareceptor in Mink Lung Epithelial Cells," Journal of Biological Chemistry, Vol. 274, No. 10, 1999, pp. 67116717. http://dx.doi.org/10.1074/jbc.274.10.6711

[13] L. C. Giudice, E. M. Farrell, H. Pham, et al., "InsulinLike Growth Factor Binding Proteins in Maternal Serum throughout Gestation and in the Puerperium: Effects of a Pregnancy-Associated Serum Protease Activity," The Journal of Clinical Endocrinology \& Metabolism, Vol. 71, No. 4, 1990, pp. 806-816. http://dx.doi.org/10.1210/jcem-71-4-806

[14] P. Angelloz-Nicoud, C. Lalou and M. Binoux, "Prostate Carcinoma (PC-3) Cell Proliferation Is Stimulated by the 22 - 25-kDa Proteolytic Fragment (1-160) Andinhibited by the 16-kDa Fragment (1 - 95) of Recombinant Human Insulin-Like Growth Factor Binding Protein-3," Growth Hormone \& IGF Research, Vol. 8, No. 1, 1998, pp. 71-75.

[15] H. Shahjee, N. Bhattacharyya and G. Zappala, "An N-Terminal Fragment of Insulin-Like Growth Factor Binding
Protein-3 (IGFBP-3) Induces Apoptosis in Human Prostate Cancer Cells in an IGF-Independent Manner," Growth Hormone \& IGF Research, Vol. 18, No. 3, 2008, pp. 188197.

[16] Y. Oh, H. L. Muller, L. Ng and R. G. Rosenfeld, "Transforming Growth Factor-Beta-Induced Cell Growth Inhibition in Human Breast Cancer Cells Is Mediated through Insulin-Like Growth Factor-Binding Protein-3 Action," Journal of Biological Chemistry, Vol. 270, No. 23, 1995 , pp. 13589-13592.

http://dx.doi.org/10.1074/jbc.270.23.13589

[17] Z. S. Gucev, Y. Oh, K. M. Kelley and R. G. Rosenfeld, "Insulin-Like Growth Factor Binding Protein 3 Mediates Retinoic Acid- and Transforming Growth Factor Beta 2Induced Growth Inhibition in Human Breast Cancer Cells," Cancer Research, Vol. 56, 1996, pp. 1545-1550.

[18] G. R. Devi, D. L. Graham, Y. Oh and R. G. Rosenfeld, "Effect of IGFBP-3 on IGF and IGF-Analogue-Induced Insulin-Like Growth Factor-I Receptor (IGFIR) Signalling," Growth Hormone \& IGF Research, Vol. 11, No. 4, 2001, pp. 231-239. http://dx.doi.org/10.1054/ghir.2001.0231

[19] C. Lalou, C. Lassarre and M. Binoux, "A Proteolytic Fragment of Insulin-Like Growth Factor (IGF) Binding Protein-3 That Fails to Bind IGFs Inhibits the Mitogenic Effects of IGF-I and Insulin," Endocrinology, Vol. 137, No. 8, 1996, pp. 3206-3212.

http://dx.doi.org/10.1210/en.137.8.3206

[20] K. W. Colston, C. M. Perks, S. P. Xie and J. M. Holly, "Growth Inhibition of Both MCF-7 and Hs578T Human Breast Cancer Cell Lines by Vitamin D Analogues Is Associated with Increased Expression of Insulin-Like Growth Factor Binding Protein-3," Journal of Molecular Endocrinology, Vol. 20, 1998, pp. 157-162.

[21] A. J. Butt, S. M. Firth, M. A. King and R. C. Baxter, "Insulin-Like Growth Factor-Binding Protein-3 Modulates Expression of Bax and Bcl-2 and Potentiates p53-Independent Radiation-Induced Apoptosis in Human Breast Cancer Cells," Journal of Biological Chemistry, Vol. 275, No. 50, 2000, pp. 39174-39181. http://dx.doi.org/10.1074/jbc.M908888199

[22] B. J. Boyle, X. Y. Zhao, P. Cohen and D. Feldman, "Insulin-Like Growth Factor Binding Protein-3 Mediates $1 \mathrm{Al}$ pha, 25-Dihydroxyvitamin d(3) Growth Inhibition in the LNCaP Prostate Cancer Cell Line through p21/ WAF1," Journal of Urology, Vol. 165, No. 4, 2001, pp. 1319-1324. http://dx.doi.org/10.1016/S0022-5347(01)69892-6

[23] D. R. Green, “Apoptotic Pathways: The Roads to Ruin," Cell, Vol. 94, No. 6, 1998, pp. 695-698. http://dx.doi.org/10.1016/S0092-8674(00)81728-6

[24] S. Fanayan, S. M. Firth, A. J. Butt and R. C. Baxter, "Growth Inhibition by Insulin-Like Growth Factor-Binding Protein-3 in T47d Breast Cancer Cells Requires Transforming Growth Factor-Beta (TGF- Beta) and the Type II TGF-Beta Receptor," Journal of Biological Chemistry, Vol. 275, No. 50, 2000, pp. 39146-39151. http://dx.doi.org/10.1074/jbc.M006964200

[25] S. Fanayan, S. M. Firth and R. C. Baxter, "Signaling 

Binding Protein-3 (IGFBP-3) and Its 1-97 N-Terminal Fragment in PC-3 Human Prostate Cancer Cells

through the Smad Pathway by Insulin-Like Growth Factor-Binding Protein-3 in Breast Cancer Cells. Relationship to Transforming Growth Factor-Beta 1 Signaling," Jour- nal of Biological Chemistry, Vol. 277, No. 9, 2002, pp. 7255-7261. http://dx.doi.org/10.1074/jbc.M108038200 